\title{
The Simulation of Hydraulic Synchronous Lift of Heavy Loads
}

\author{
Lubica Miková*, Michal Kelemen, Peter Ujhelský, Alexander Gmiterko \\ Technical University of Košice, Faculty of Mechanical Engineering, Department of Applied Mechanics and Mechatronics, Košice, Slovakia \\ *Corresponding author: lubica.mikova@tuke.sk
}

Received September 12, 2014; Revised September 19, 2014; Accepted October 03, 2014

\begin{abstract}
Synchronous hydraulic machinery are intended (alebo utilised) to lift heavy building structures but also other heavy loads. The goal of this paper is to establish overview of utilisation of synchronous lifting in practice and the proposal for hydraulic system which provides synchronous lift of heavy load. According to type of operation it is possible to choose specific hydraulic kit. The main parameters are load capacity and lifting height.
\end{abstract}

Keywords: hydraulic circuits, synchronous lift

Cite This Article: Lubica Miková, Michal Kelemen, Peter Ujhelský, Alexander Gmiterko, and Alexander Gmiterko, "The Simulation of Hydraulic Synchronous Lift of Heavy Loads.” American Journal of Mechanical Engineering, vol. 2, no. 7 (2014): 191-194. doi: 10.12691/ajme-2-7-4.

\section{Introduction}

Hydraulic drives take a significant part in various sectors, including machinery for production, transportation and material handling, construction machinery, equipment for the lifting machinery and entertainment industry, in spite of the increasing competition from electric drives. There is no other place where one can find as much hydraulics as in the moving work machines. A drive that is electrical must be connected to the electricity network, which is not possible in the case of a mobile work machine. Therefore, a high-pressure pump represents a great advantage due to its easy connection to a combustion engine. Another fact is that a pump has a much smaller size than an electric motor of similar or identical power. Another advantage is represented by a hydraulic cylinder, which is owing to its characteristics the simplest way of creating the linear motion.

\section{The Structure of Hydraulic Circuits}

Technological equipment, as for example machines, is made up of several kinds and types of mechanisms. A mechanism is created as a system which is designed to transfer energy between its inlet and outlet or, in other words, between the driving part and the part that is being driven. For machines with automatic control, the mechanism must also provide the transmission of information that is needed to control the machine or technological equipment. The mechanism is actually made up of input and output converters which are connected by a transmission channel, and of the control block which is used to control the required parameters. If the energy is transmitted by a mechanism that is between the driving part and the part that is being driven and the information is transmitted by fluid or some other substance in the liquid state, we are talking about a hydraulic mechanism or, in other words, a fluid mechanism. A lot of machines are composed of several mechanisms that can use different kinds of energy. The hydraulic drive is a part of the hydraulic mechanism that is intended to power machines and mechanisms. The basic parts of a hydraulic circuit that play the role in the transmission of pressure energy are called hydraulic components. The assemblage of hydraulic components such as pumps, control components and distributors and accessories which provide a required function are called the hydraulic circuit.

Hydraulic drives are divided into two basic categories: hydrostatic drives and hydrodynamic drives.

- Hydrostatic drives - they are the more used ones and they use the pressure energy of the fluid to transmit energy and information.

- Hydrodynamic drives - they mainly use the kinetic energy of the fluid $[1,2,3]$.

\section{Synchronous Lift}

Hydraulic system could be used for lifting a heavy building structure which would demand at least one pair of hydraulic actuators. The position of any complex structure regardless of weight distribution is controlled by means of sensors.

The advantage of synchronous lift is that it reduces the risk of bending, twisting or tilting when the weight is distributed unevenly between the lifting points. It is possible to monitor each shift during lifting by means of the control unit of the PLC and position sensors that are located at each lifting point. The system can provide accurate position regulation by changing the flow of hydraulic fluid at each of its lifting points. This control 
method can maintain the structural integrity and increase productivity and safety of lifting by eliminating manual actions in case of load displacement or other problems.

Synchronous lift is commonly used for:

- lifting bridges due to maintenance (replacement of bearings)

- lifting, lowering and balancing heavy structures

- measuring the centre of gravity

- gradual shifting of bridge structures and final clamping of bridges

- installation of heavy equipment $[4,5,6]$.

\subsection{The Example of Usage in Slovakia}

One of the most important structures constructed in this way is the Apollo Bridge located in Bratislava. Its construction was carried out from 2002 to 2005. This Bratislava bridge named Apollo became famous around the world mainly due to its capability to rotate its main bridge field, which weighed approximately 5,200 tons, across the river Danube. The rotation of the bridge body, which was placed on the floating pontoons, across the Danube from its left bank, represented an unprecedented peculiarity. In order to carry out an operation like this, it was necessary to take a number of steps as for example to stabilize the water level of the Danube by the Gabcikovo waterworks (without which the similar way of construction wouldn't be possible).

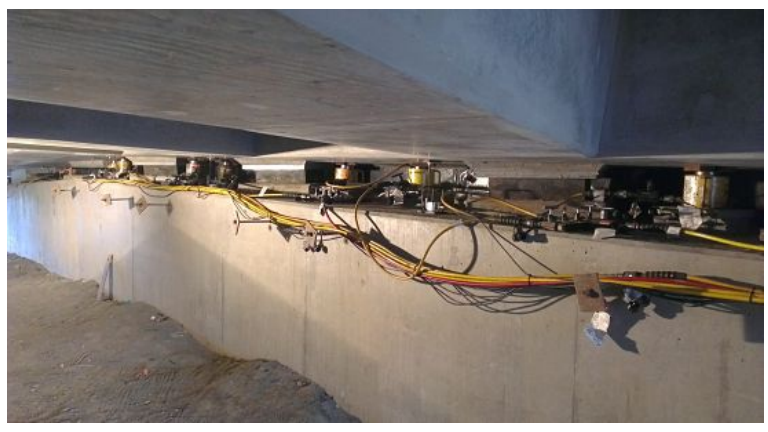

Figure 1. Construction of the bridge [7]

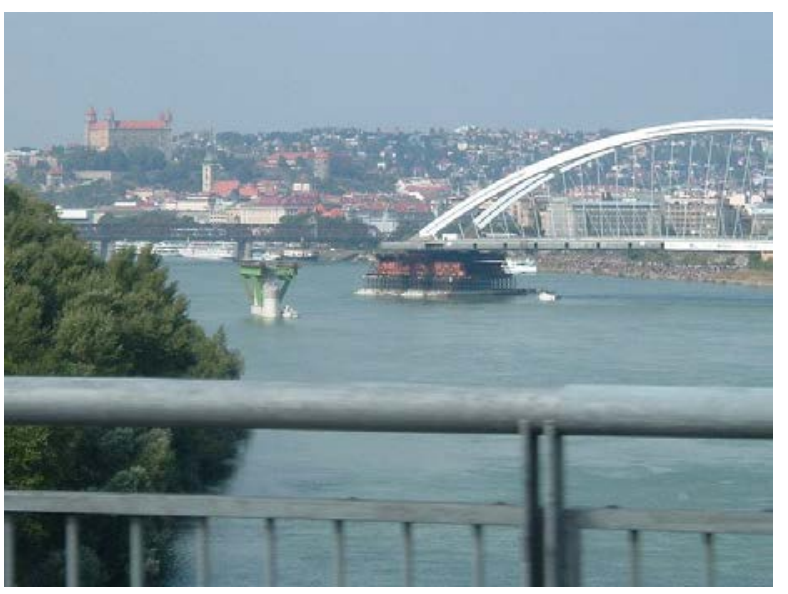

Figure 2. The rotation of the Apollo Bridge [8]

\subsection{The Example of Usage Abroad}

Another example of usage of the hydraulic lifting system is from abroad. In the USA, it is very popular to move entire houses. Also in this case, the relocation of such large, heavy and bulky object would be impossible without the use of hydraulic system. In America, houses are usually built of wood and their only concrete parts are the foundations. Therefore, it is easy to disconnect the wooden part (of the house) from the concrete base. The advantage of this moving is that the whole complex can be relocated to another place.

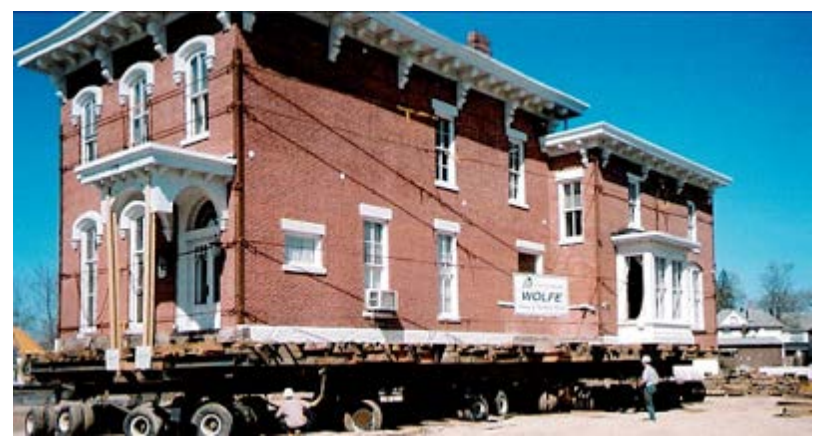

Figure 3. Relocation of a house [11]

\subsection{The Example of Synchronous Lift on Transport Communications}

When it comes to transport communications, maintenance and repairs to the bridges are very important owing to the ever increasing traffic. Nowadays, the constructions of new bridges or repairs to them are carried out exclusively by hydraulics. Using hydraulics, bridge structures can be lifted but also let down or they can be manipulated with in some other way. The most common operation that is carried out when bridges are being lifted is the replacement of the bearings. In most cases, this operation is very easy but only if the bridge structure is not very complicated.

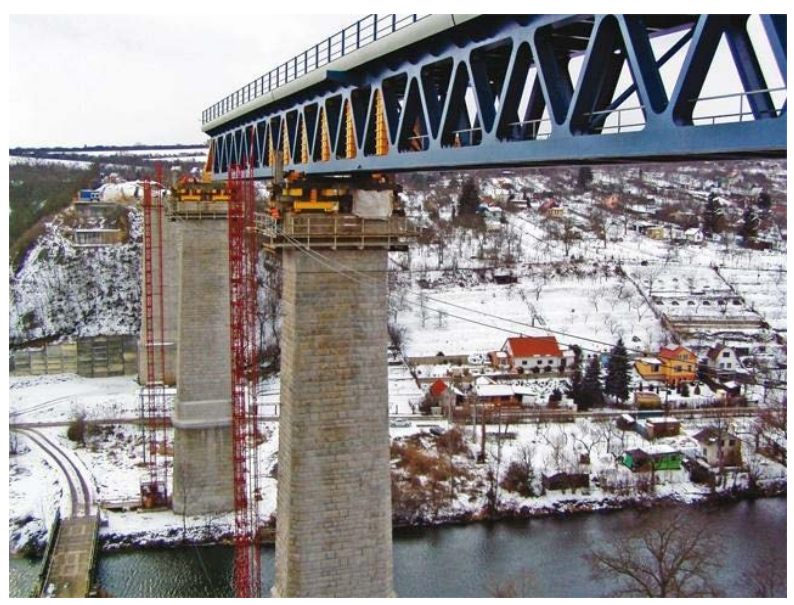

Figure 4. Replacement of a bridge structure

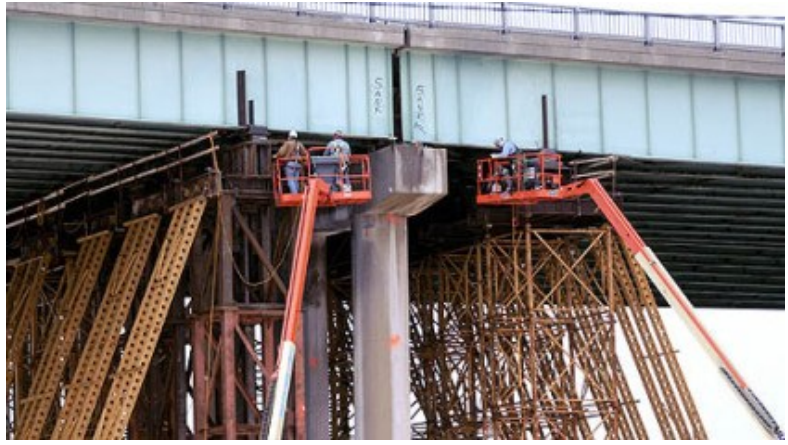

Figure 5. Lift of a bridge in order to repair the bearings [10] 


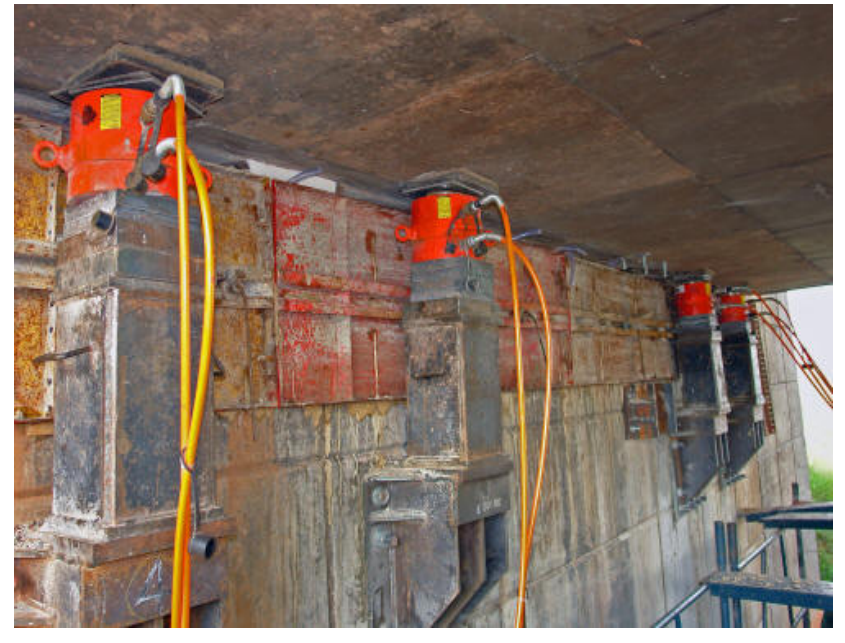

Figure 6. Detail of the lift of a bridge [9]

\section{Arranging for the Synchronous Lift}

Synchronous lift system components consist of a control unit, sensors and hydraulic equipment. The sensors achieve a high accuracy of measurement. Using the control unit, it is possible to change several settings as for example the setting of the initial "zero" position or the setting of the allowed regulation deviation. The regulation system is two-positional which means that each pressure output is controlled by the solenoid valve. The most commonly used is the regulation of fluid pressure of synchronous lift by solenoid valves. The high-pressure pump is one of the main components that comprise the system. The solenoid valves constitute the main part of this method. These valves are designed to regulate the flow and they consist of three basic components which are the connector, the valve body and the coil.

A scheme for 4 up to 64-point lift systems. This system is capable of controlling up to 64 lift points and it can be used with both single and double-acting hydraulic cylinders.

It is possible to program this system so that each hydraulic cylinder simultaneously performs a different lift.

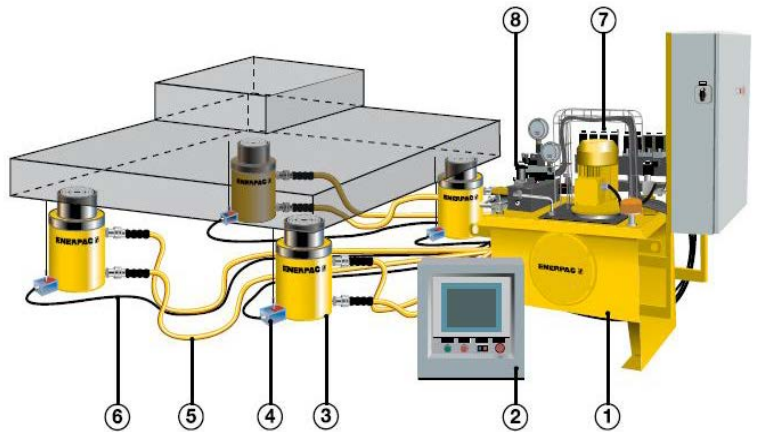

Figure 7. A diagram of a 4-point synchronous lift system [12]

1. Hydraulic pump

2. Control unit of the PLC with touch screen

3. Hydraulic cylinders

4. Lift sensors

5. Hydraulic hoses

6. Sensors' cables

7. Solenoid control valves

8. Pressure sensor.

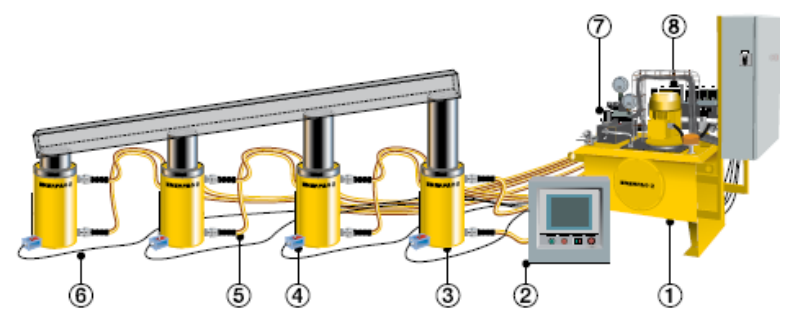

Figure 8. Tilting performed by the programmed hydraulic cylinders [12]

1. Hydraulic pump

2. Control unit of the PLC with touch screen

3. Hydraulic cylinders

4. Lift sensors

5. Hydraulic hoses

6. Sensors' cables

7. Solenoid control valves

8. Pressure sensor

In hydraulic systems, lift height is controlled by sensors. These position sensors measure the coordinates of a particular point within the system.

\section{Proposal for a Hydraulic System}

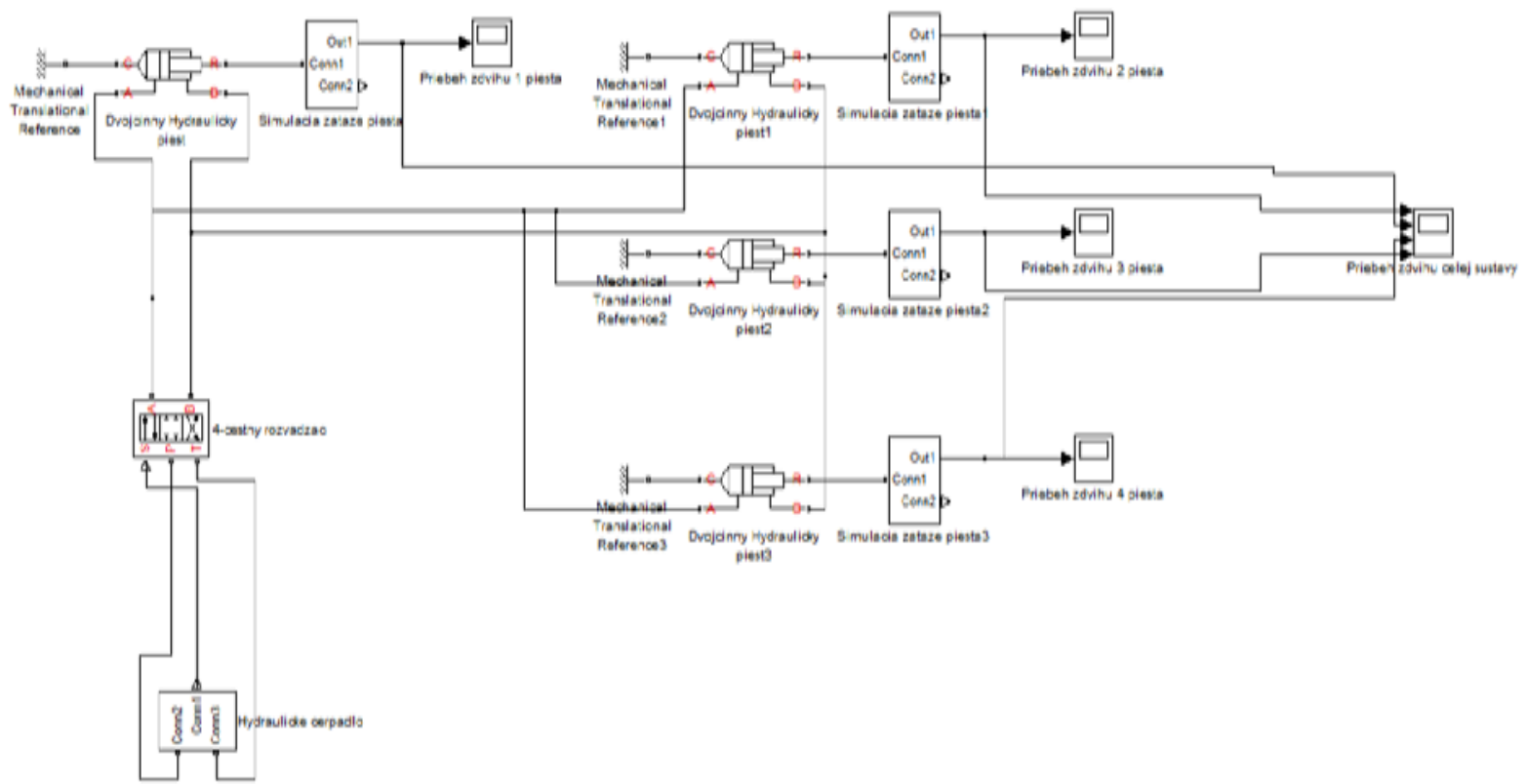

Figure 9. A diagram designed in Matlab 
The aim of the proposal for a hydraulic system is to propose a system capable of providing synchronous lift of heavy loads. In order to maintain security, the proposed system should use a maximum of $80 \%$ of its power. Cylinders must be placed stably on smooth and flat surfaces. Load's fulcrum must be stable and centered on the cylinder's axis.

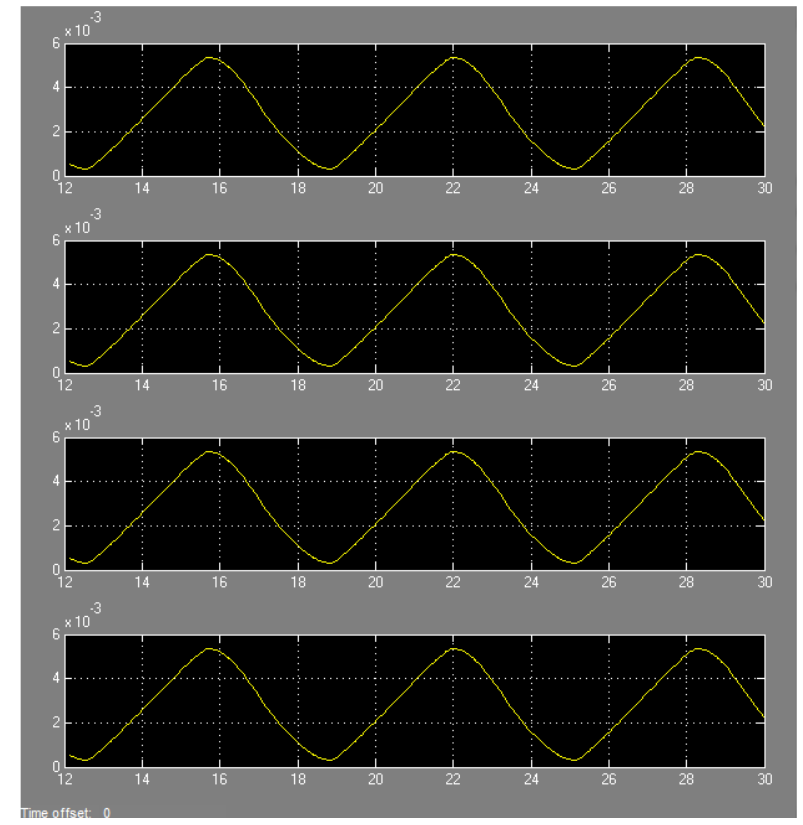

Figure 10. The resulting graphs that capture a 30 second spans using simulation

A program called Matlab with an extension called Simhydraulics provides a variety of components for modeling and simulations of hydraulic systems. It includes many hydraulic components such as pumps, valves, drives, piping and hydraulic resistance. These components can be used to model hydraulic systems, in our case, to model hydraulic systems for synchronous lift of loads. The models that have been designed in Simhydraulics can be used for developing control systems and for performing tests within the system. The models can be parameterized using expressions and variables. Also, it is possible to add a variety of mechanical, electrical and pneumatic components to the hydraulic model.

\section{Conclusions}

Options for lifting and lowering using this system are unlimited. Synchronous lift or lowering or pushing and easy setting at any position is provided by a modern computer technology. The appropriate addition of hydraulic actuators can enable the system to lift even loads with a weight of 50,000 tons while still maintaining a high level of security and accuracy. Without the use of such hydraulic equipment, it would be difficult to construct certain buildings and building structures as for example bridges.

\section{Acknowledgements}

This contribution is a result of the project Slovak Grant Agency - project VEGA 1/0937/12. Development of nontraditional experimental methods for mechanical an mechatronical systems" and University Science Park Technicom ITMS 26220220182.

\section{References}

[1] MANRIN, D. NOAH : Hydraulic control systems. London, 2005.

[2] HOREVAJOVÁ, Jaroslava : Elektronické systémy 1.diel. ČVUT, 1981.

[3] RÝC, Zdeněk - PAVLOK, Bohuslav : Hydraulické pohony a jejich regulace. Ostrava, 1984.

[4] NOSKIEVIČ, Petr: Modelovaní a identifikace systémú. Ostrava : Montanex, 1999.

[5] ISERMANN, Rolf: Mechanic systems fundamentals. London : Spinger - Verlag, 2003.

[6] MATIČKA, Robert - VOSTROVSKÝ, Jiří : Hydraulické prvky. Praha 1, 1974

[7] http://www.coateshire.com.au/About-Coates/News/newsynchronous-jacking-system-makes-light-work-of.

[8] https://www.flickr.com/photos/97035860@N04/10623029525/.

[9] http://www.hyhold.co.za/News/2009/August/002.htm.

[10] http://www.post-gazette.com/local/2008/03/02/Part-ofBirmingham-Bridge-may-reopen-6-a-mtomorrow/stories/200803020203.

[11] http://wolfehousebuildingstructuralmoverspa.blogspot.sk/.

[12] www.enerpac.com. 